\title{
Magnetic Resonance Imaging of Osteo-Articular System at the Douala General Hospital
}

\author{
Mathurin Neossi Guena1,2*, Florent Alapha Zilbinkai², Gilbert Tongouvda1, \\ Emmanuela Manka'a Wankie ${ }^{3}$, Narcisse Nwedjiwe Nana ${ }^{3}$, Celestine Nguemgne ${ }^{3}$, \\ Wanko Woguep Laure Vanina ${ }^{3}$, Joseph Fotsin Gonsu ${ }^{4,5}$ \\ ${ }^{1}$ Department of Biomedical Sciences, Faculty of Sciences, University of Ngaoundéré, Ngaoundéré, Cameroon \\ ${ }^{2}$ Imaging Service, Ngaoundéré Regional Hospital, Ngaoundéré, Cameroon \\ ${ }^{3}$ Imaging Service, Douala General Hospital, Douala, Cameroon \\ ${ }^{4}$ Faculty of Medicine and Biomedical Sciences, University of Yaounde I, Yaounde, Cameroon \\ ${ }^{5}$ Yaounde Gynaecology Obstetrics and Pediatrics Hospital, Yaounde, Cameroon \\ Email: *mneossiguena@yahoo.fr
}

How to cite this paper: Guena, M.N. Zilbinkai, F.A., Tongouvda, G., Wankie, E.M., Nana, N.N., Nguemgne, C., Vanina, W.W.L. and Gonsu, J.F. (2019) Magnetic Resonance Imaging of Osteo-Articular System at the Douala General Hospital. Open Journal of Radiology, 9, 139-150. https://doi.org/10.4236/ojrad.2019.92013

Received: May 9, 2019

Accepted: June 23, 2019

Published: June 26, 2019

Copyright $\odot 2019$ by author(s) and Scientific Research Publishing Inc. This work is licensed under the Creative Commons Attribution International License (CC BY 4.0).

http://creativecommons.org/licenses/by/4.0/

\begin{abstract}
Objectives: Osteoarticular pathology has benefited greatly from MRI. This modality was only recently introduced in our country and its implantation is still rare. The objective of this study was to evaluate the practice of MRI of osteoarticular system in Douala General Hospital. Method: It was a cross-sectional descriptive study during a five-month period from May to September 2017 involving all patients referred to the Imaging Department of the Douala General Hospital for osteoarticular MRI. All the patients were scanned using an open-sided mid-field MRI APERTO LUCENT (0.4 T) using axial, sagittal and coronal slices in T1-weighted, T2-weighted proton density. T1 gadolinium or water-fat saturation (WFS) slices were obtained after injection of a contrast agent (Dotarem). Collected data were analyzed using SPSS v20 and Microsoft Excel 2010 softwares. Results: 34 patients were enrolled in this study; osteoarticular MRI accounted for $12 \%$ of the activity behind MRI of the spine (40.4\%) and the brain (42.5\%). The mean age of patients was $37.6 \pm 13.1$ years with extremes between 6 and 61 years. There was male predominance with a sex ratio of 1.83 . Trauma (44.2\%) and pain (42.1\%) were the most common indications. MRI of the lower limb (85.3\%) and more particularly of the knee (68.9\%) was more frequently performed than that of the upper limb (14.7\%). Orthopedic surgeons (38.2\%) and rheumatologists (26.5\%) were the main referral physician. $73.5 \%$ of request's forms did not conform to the eight compliance criteria according to the recommendations of French National Agency for Accreditation and Health Evaluation. Most of the examinations (94.1\%) were performed without the injection of contrast agent (Dotarem). 97\% of MRI was pathological. Traumatic pathologies (39.4\%) were most fre-
\end{abstract}


quent and concerned the knee (27.3\%) and the ankle/feet (12.1\%), followed by the degenerative pathologies $(21.2 \%)$ which concerned the knee $(18.2 \%)$ and hip joints $(3 \%)$, inflammatory pathologies $(12.1 \%)$ reaching the shoulder (9.1\%) and wrist/hand (3\%) while tumoral pathologies (6\%) were reaching the knee (3\%) and the leg (3\%). Conclusion: The MRI of the osteoarticular system is quite common, ranking third after the MRI of the spine and the brain. This study showed that MRI has a significative impact on diagnosis of osteoarticular diseases whit a concordance of $97 \%$ with clinic.

\section{Keywords}

MRI, Osteoarticular System, Douala General Hospital

\section{Introduction}

The osteo-articular system corresponds to all the anatomical structures that support the human body. It includes bone skeleton, joints and muscles. It is a system that is permanently exposed to different pathologies. In addition to the natural wear that can cause pain and impotence, traumatic, inflammatory and tumoral lesions can affect the musculoskeletal system [1] [2] [3]. MRI has now become the gold standard for the study of osteoarticular pathology and is the second indication after that of the central nervous system [1]. Although magnetic resonance imaging (MRI) has been used initially for clinical problems other than those affecting the osteoarticular apparatus, it is now routinely used for imaging bone, joint and soft tissue lesions [4] [5] [6] [7]. Plain X-ray remains the most widely used technique in the world and in some resource-poor countries they remain the only means of exploration for the majority of bone lesions. Thus X-rays, and often ultrasound, are practiced beforehand, which is why MRI is in most cases "the first technique of second intention". Several authors have demonstrated the interest and sensitivity of MRI in the assessment of trauma and osteoarticular tumoral lesions [8] [9] [10]. In Cameroon, there is not yet a study that has been done on the use of such a technique in osteoarticular pathologies. However the MRI is not yet popularized and is still taking its first steps in our country where availability is scarce. Because of its recent introduction in our country, we conducted this study to evaluate the practice of MRI of osteoarticular system in the Douala General Hospital and to identify local specificities.

\section{Method}

It was a cross-sectional descriptive study, carried out at the Department of Radiology of the Douala General Hospital (HGD) between May and September 2017. Were included in this study any patient presenting at the General Hospital of Douala for MRI of any part of the osteoarticular system, who do not present contraindications to this examination and who freely consents to participate in 
this study. Patients with contraindications to MRI were excluded from this study as were those who declined to participate in the study. The conformity of MRI request was analyzed by checking the elements of conformity of the request (Table 1) according to the recommendations of French National Agency for Accreditation and Health Evaluation (NAAHE).

Previous medical imaging examinations were also checked. All the patients were scanned using an open-sided mid-field MRI APERTO LUCENT (0.4 T). After the preparation of the patient (explanation, verification of history of allergic reactions, removal of all metal items, wearing of a hospital gown), they were examined with the following protocol: After a tracking sequence in all 3 plans, to ensure correct positioning of slices, axial, sagittal and coronal slices in T1-weighted, $\mathrm{T} 2$-weighted and proton density images were obtained. When needed, T1 gadolinium or water-fat saturation (WFS) slices were obtained after injection of 0.1 $\mathrm{ml} / \mathrm{kg}$ of a contrast agent (Dotarem). The interpretation was performed by a radiologist and the result exploited as part of this study. The data was collected using a data fact sheet previously prepared and processed with SPSS v20 and Microsoft Excel 2010 software.

\section{Results}

During the study period, 34 osteoarticular MRIs were performed, representing $12 \%$ of the overall activity, behind the spine MRI (40.4\%) and the brain (42.5\%).

\section{- Patient profile}

Our sample consisted of 12 women and 22 men, a sex ratio of 1.83 . The average age was $37.6 \pm 13.1$ with extremes between 6 and 61 years. Figure 1 shows that the most represented age groups were those aged 30 - 39 and 40 - 49 years with $29.4 \%$ and $26.4 \%$, respectively.

\section{- Exam data}

The lower limbs (85.3\%) were more explored with a predominance of the knee at $58.8 \%$ of cases (Table 2) followed by hip joints, ankle and foot with $11.8 \%$ each.

Table 1. Elements of conformity of the request (NAAHE).

\begin{tabular}{l}
\hline Elements of conformity of the request \\
\hline Administrative criteria \\
- Request date \\
- Service applicant \\
- Identification of referring physician \\
- Patient's identification \\
- Patient's date of birth or age \\
Clinical criteria \\
- Anatomical explored region \\
- Exam indication (clinical history) \\
- Finality of the examination (diagnostic impression) \\
\hline
\end{tabular}




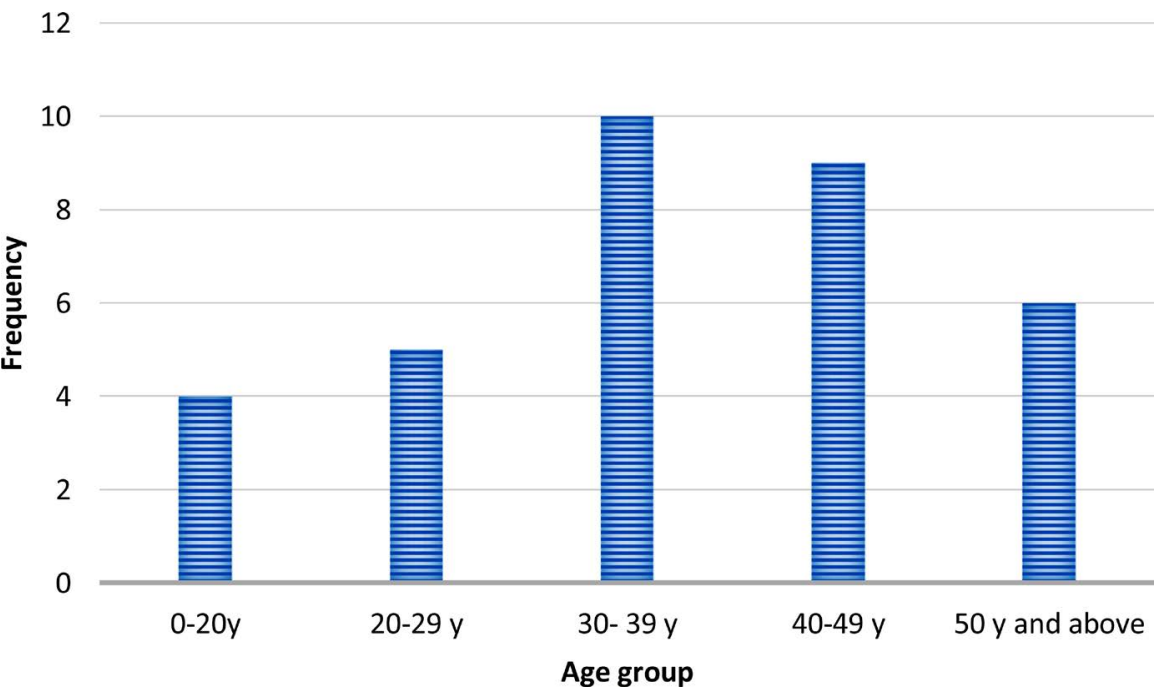

Figure 1. Distribution of patients by age.

Table 2. Distribution of patients by explored parts.

\begin{tabular}{ccc}
\hline Explored part & Frequency & Percentage (\%) \\
\hline Knee & 20 & 58.8 \\
Hip joints & 4 & 11.8 \\
Ankle and foot & 4 & 11.8 \\
Shoulder & 3 & 8.8 \\
Elbow & 1 & 2.9 \\
Leg & 1 & 2.9 \\
Wrist and hand & 1 & 2.9 \\
Total & 34 & 100 \\
\hline
\end{tabular}

Trauma (44.1\%) and pain (41.2\%) were the common indications (Table 3).

Orthopedic surgeons (38.2\%) and rheumatologists (26.5\%) were the main referral physician. $73.5 \%$ of request's forms were not conform to the eight compliance criteria according to the recommendations of French National Agency for Accreditation and Health Evaluation. Standard radiography (79.4\%) was the most common previous examination followed by ultrasound with $11.7 \%$ and CT scan with $2.9 \%$.

Most of the examinations $(94.1 \%)$ were performed without the injection of contrast agent (Dotarem).

Concerning results, of 34 MRIs performed, 33 were abnormal corresponding to $97 \%$. One patient had multiple lesions at a time, traumatic pathologies $(85.29 \%)$ were most frequent and concerned the knee (44.11\%) and the ankle/feet (14.70\%), followed by the degenerative pathologies (35.29\%) which concerned the knee (20.58\%) and hip joints (8.82\%), inflammatory pathologies $(35.29 \%)$ reaching the shoulder (11.76\%) and wrist/hand (2.94\%) while tumoral pathologies $(17.64 \%)$ were reaching the ankle/foot (11.76\%) (Table 4). Other pathologies accounted 
for $26.47 \%$.

The predominant lesions were articular fluid effusion (26.4\%) followed by contusion (17.6\%), cartilaginous degenerations (17.6\%), cysts (17.6\%), meniscal rift (14.7\%) and tendinopathy (14.7\%) (Table 5).

\section{- Images}

Figures 2-5 show examples of anomalies encountered so Figure 2 shows fracture of tibial metaphysis and small effusion in the ankle joint, Figure 3 shows knee effusion and cyst of distal femoral metaphysis, Figure 4 shows glenoid bursitis and effusion, Figure 5 shows an encysted hematoma with central calcification and fatty infiltration of the muscles of the posterior compartment of the leg.

\section{Discussion}

Osteoarticular MRI accounted for $12 \%$ of overall activity, behind spine MRI (40.4\%) and brain (42.5\%). According to the High Authority of Health in France(HAH), in 2009 the bone and joint MRI accounted for $40 \%$ of overall activity in France, 25\% in Canada and Belgium, 24\% in the USA, 10\% in Austria, and $8 \%$ in Germany [8]. This is a relatively frequent exam. Ould Beddi in 2006 had found $6.4 \%$ [9]. In our study, knee MRI represents $7.2 \%$ of overall activity, which is similar to that of Adjenou et al. 2011 who found 7\% [10]. The osteo articular MRI both in our country and elsewhere occupies an important place.

Table 3. Distribution of patients according to Exams indications.

\begin{tabular}{ccc}
\hline Indications & Frequency & Percentage (\%) \\
\hline Traumatism & 15 & 44.1 \\
Articular pain & 14 & 41.2 \\
Not mentioned & 2 & 5.9 \\
Swelling & 2 & 5.9 \\
Ulnar tunnel syndrom & 1 & 2.9 \\
Total & 34 & 100 \\
\hline
\end{tabular}

Table 4. Distribution of patients by groups of pathologies.

\begin{tabular}{cccccc}
\hline Pathology Region & Traumatic & Degenerative & Inflammatory & Tumoral & Other \\
\hline Shoulder & $1(2.94 \%)$ & $1(2.94 \%)$ & $4(11,76 \%)$ & 0 & 0 \\
Elbow & $1(2.94 \%)$ & $1(2.94 \%)$ & $1(2.94 \%)$ & 0 & $1(2.94 \%)$ \\
Wrist/hand & $1(2.94 \%)$ & 0 & $1(2.94 \%)$ & 0 & $1(2.94 \%)$ \\
Hip joints & $3(8.82 \%)$ & $3(8.82 \%)$ & $2(5.88 \%)$ & 0 & $4(11.76 \%)$ \\
Knee & $15(44.11 \%)$ & $7(20.58 \%)$ & $3(8.82 \%)$ & $1(2.94 \%)$ & $3(8.82 \%)$ \\
Leg & $3(8.82 \%)$ & 0 & 0 & $1(2.94 \%)$ & 0 \\
Ankle/foot & $5(14.70 \%)$ & 0 & $1(2.94 \%)$ & $4(11.76 \%)$ & 0 \\
Total & $29(85.29 \%)$ & $12(35.29 \%)$ & $12(35.29 \%)$ & $6(17.64 \%)$ & $9(26.47 \%)$ \\
\hline
\end{tabular}


Table 5. Distribution of patients by Identified lesions.

\begin{tabular}{|c|c|c|}
\hline Identified lesion & Frequency & Percentage (\%) \\
\hline \multicolumn{3}{|l|}{ Traumatic lesion } \\
\hline - Articular fluid effusion & 9 & 26.4 \\
\hline - Fracture & 4 & 11.7 \\
\hline - Contusion & 6 & 17.6 \\
\hline - Hematoma & 2 & 5.8 \\
\hline - Rift of posterio cruciate ligament & 1 & 2.9 \\
\hline - Rupture of tendon & 2 & 5.8 \\
\hline - Meniscal rift & 5 & 14.7 \\
\hline \multicolumn{3}{|l|}{ Inflamatory lesion } \\
\hline - Tendinopathy & 5 & 14.7 \\
\hline - Bursitis & 4 & 11.7 \\
\hline - Osteochondritis & 3 & 8.8 \\
\hline \multicolumn{3}{|l|}{ Degenerative lesion } \\
\hline - Cartilage degeneration & 6 & 17.6 \\
\hline - Coxo-femoral remodeling & 1 & 2.9 \\
\hline - Epiphysiolysis & 1 & 2.9 \\
\hline - Avascular necrosis of the femoral head & 1 & 2.9 \\
\hline - Meniscal degenerative process & 3 & 8.8 \\
\hline Tumoral lesion & 6 & 17.6 \\
\hline \multicolumn{3}{|l|}{ Other lesion } \\
\hline - Cyst & 6 & 17.6 \\
\hline - Ulnar tunnel syndrom & 1 & 2.9 \\
\hline - Intra articulr foreign body & 1 & 2.9 \\
\hline - Algodystrophy & 1 & 2.9 \\
\hline Normal exam & 1 & 2.9 \\
\hline
\end{tabular}

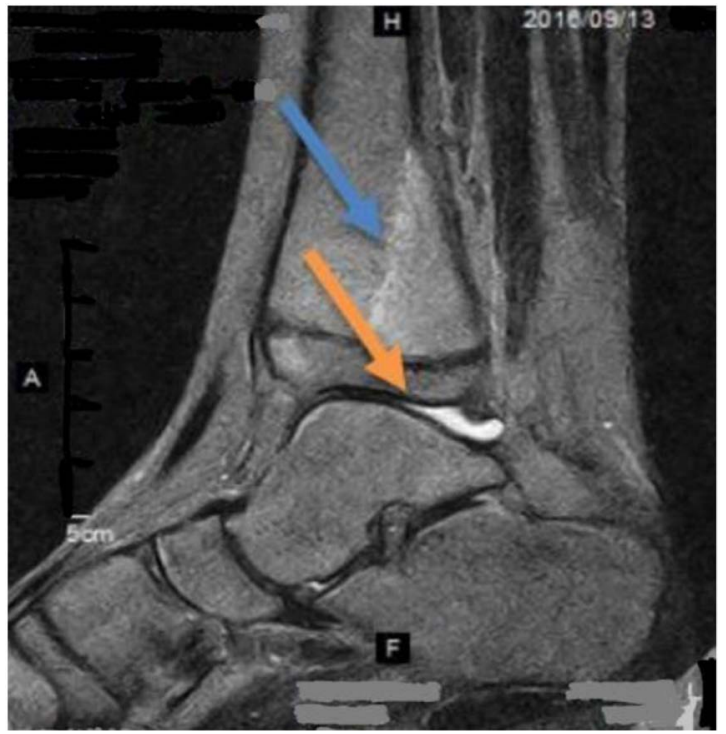

Figure 2. Fracture (blue arrow) of tibial metaphysis and a small effusion (red arrow) on Sag T2 W image of the ankle. 


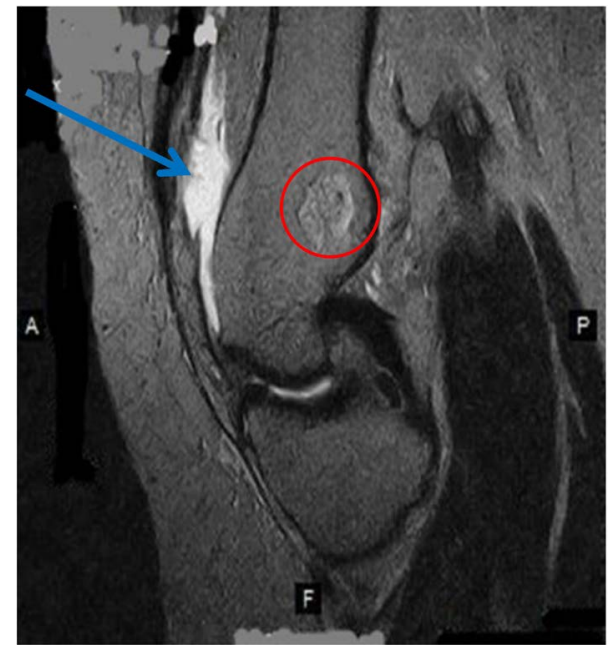

Figure 3. Joint effusion (blue arrow) and a cyst of the femoral metaphysis (red circle) on Sag T2 W image of the knee.

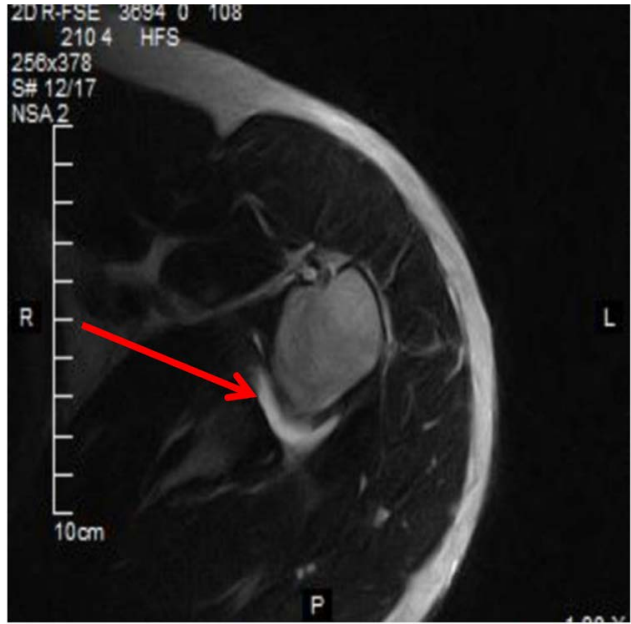

Figure 4. Glenoid bursitis with effusion (red arrow) on Axial T2 W image of shoulder.

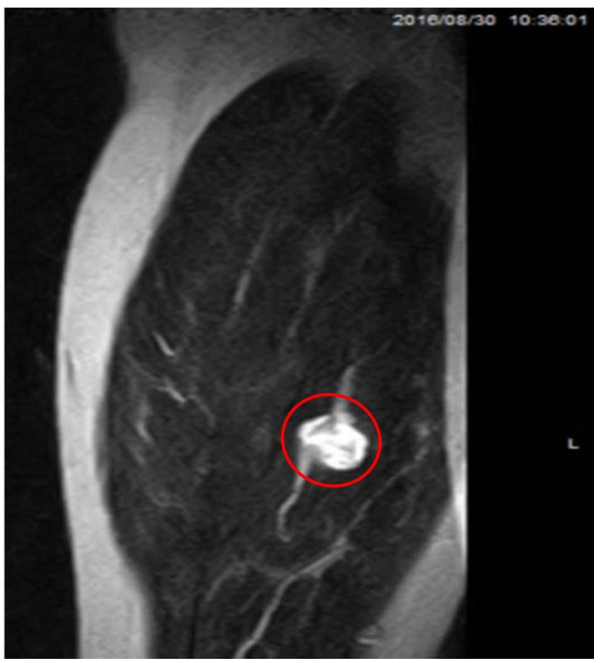

Figure 5. An encysted hematoma with central calcification and fatty infiltration (red circle) on a frontal $\mathrm{T} 2 \mathrm{~W}$ of the muscles of the posterior compartment of leg. 


\section{- Epidemiological profile}

There was a male predominance with a sex ratio of 1.83 . This could be explained by the high rate of trauma in our study that affected more men than women [11]. This rate is slightly higher than those found by Adjenou et al., Douira et al. who found a sex ratio of 1.7 and 1.6 respectively [10] [12]. Our study population was aged of 6 to 61 years with an average age of 37.6 years. This is the age group where the activity is greater exposing populations to trau$\mathrm{ma}$ and wear that reaches the osteoarticular system. These results are close to those of Mrabti et al., who had an average age of 40 years [13]. Indeed, osteoarticular pathologies occur at any age. However, it mostly reaches people over 40 years, because the majority of osteo-articular disorders appear with age as is the case of degenerative diseases [14].

\section{- Exam data}

MRI examinations of the lower limbs (85.3\%) and more particularly the knee (58.9\%) were more frequent than those of the upper limbs (14.7\%). This finding was also made by the French High Authority of Health (HAH) who found that the exploration of the lower limbs (and in particular the knee) was four times more frequent than the upper limbs [8]. The French Regional Health Agency (RHA) reported the proportions of $31 \%$ against $5 \%$ of the acts respectively for the lower and upper limbs [14]. This can be explained by the fact that the lower limbs support the entire weight of the body and are subject to exceptional forces during sports activities such as running, jumping, football, basketball and which may be more affected by different pathologies.

The main indications in our study were trauma (44.1\%) and pain (41.2\%). The French High Authority of Health (HAH) had classified MRI indications of limbs into three groups; the first concerns pains with normal radiographs or litthe contributory, the second group mentions trauma and finally particular indications in the case of rheumatoid arthritis, meniscal lesions and associated lesions of the anterior cruciate ligament of the knee in adults [8]. The prevalence of trauma is due to the young age of our population ( $82.2 \%$ under 50 years), according to World health Organization (WHO), it is between 5 and 44 years that the rate of trauma is dominant as in our study [11]. As for the pain, it is a symptom common to all the diseases and of which in general frequent.

The majority of examinations in our study were requested by orthopedic surgeons (38.2\%) and rheumatologists (26.5\%). This is quite normal because of their specialty; they are more concerned with osteoarticular pathologies and moreover qualified for the accomplishment of such a task. According to the Guide for the Good Use of Imaging Examinations, MRI examinations are qualified as specialized examinations, which should be requested by the specialists of the bodies concerned. Indeed, these are complex or expensive examinations that are performed only on the request of physicians with the required experience and clinical expertise to integrate the results of imaging for appropriate management of the patient [15]. This is why the request for this examination should 
not suffer from any failure in terms of the review criteria. Paradoxically, $73.5 \%$ of the request's forms did not conform to the eight compliance criteria according to the recommendations of French Society of Radiology (15). There was no indication in $20.6 \%$ of requests form, $52.9 \%$ of examinations had no purpose and $5.8 \%$ of examinations had no indication and no purpose. However, the indication is the key element of a request form in medical imaging, it is not only an element of justification but is also an essential parameter for technical choices and in the interpretation of the images by the radiologist.

\section{- Pathologies found}

Our study revealed that $97 \%$ of MRIs were pathological. These data are similar to those reported by Ould Beddi, Adjenou et al. who were respectively $100 \%$ and $98 \%$ pathological MRI [9]. In contrast, Douira et al. found $86 \%$ pathological MRI [12]. The high frequency of pathological MRI can be explained by a good indication of this examination and by the high sensitivity and specificity of MRI in the exploration of the osteo articular system. This also reflects good agreement between the MRI and the clinic.

The osteo-articular pathologies in our study were varied and diverse, characterized by the predominance of traumatic (85.4\%) and degenerative (35.29\%) lesions. Inflammatory lesions were less frequent (35.29\%) and tumor lesions (17.64\%) were rare. The others lesions accounted for $26.47 \%$ of cases. Adjenou et al. in 2012 found 55\% degenerative lesions, $41 \%$ traumatic lesions and $2 \%$ tumoral and congenital lesions each [10]. Douira et al. in 2004 found 35\% of traumatic lesions, $22 \%$ of congenital anomalies, $16 \%$ of tumor lesions, $15 \%$ of infectious lesions and $7 \%$ of inflammatory lesions [12]. Traumatic and degenerative lesions are therefore the most represented in all series.

The knee (58.8\%), hips joints, ankle and foot (11.8\% each) were the most affected. The traumatic lesions of knee were mainly represented by joint effusions with $26.4 \%$ and meniscal lesions (14.7\%). Adjenou et al. found a predominance of meniscal lesions, followed by cartilaginous, bony and ligamentous lesions in $76.2 \%, 50 \%, 47.6 \%$ and $33.3 \%$ of cases, respectively [10]. The high number of knee meniscal lesions in our study is due to the fact that $50 \%$ of patients had traumatic or post-traumatic knees. In the ankle and foot, lesions were represented by fractures $(11.7 \%)$, contusion (17.6\%), a case of Achilles tendon rupture and of fluid effusion that may occur during trauma [16].

The degenerative lesions (35.29\%) preferentially affected the lower limbs and particularly the knee (20.58\%) and the hip joint (8.82\%). Abhishek et al. found in order of frequency the following locations: the fingers, the rachis, the knees, the hips and the first metacarpophalangeal joints [17]. Mannoni et al. in a study of an Italian population in 2003 over 65 years of age found a prevalence of $29.8 \%, 14.9 \%$ and $7.7 \%$ respectively for the knee, hand and hip joint [18]. Our study revealed a predominance of patients over 40 years of age with a single case of a 17-year-old boy with secondary hip osteoarthritis. Indeed, the risk of occurrence of these pathologies increases with age, they usually reach adult subjects. 
For many authors, these conditions occur in middle-aged or older people [18] [19].

Inflammatory lesions were present in shoulder, knee, hip joints and wrist/hand respectively in $11.76 \%, 8.82 \%, 5.88 \%$ and $2.94 \%$ of cases. They were diagnosed in the circumstances of pain ( 2 cases), swelling and trauma (one case each). Two cases of tendinitis and one case of glenoid bursitis were diagnosed at the shoulder level. A peri-tendinitis associated with a cyst was highlighted at the wrist and hand. The high frequency of tendinitis in the shoulder is also found in the literature and is due to the repetition of the gestures causing the tendon rubbing and to the poor blood supply of the tendon at this point [20] [21].

Tumor lesions were infrequent and localized mainly in the ankle/foot (11.76\%), knees (2.94\%) and hip joints (2.94\%). MRI has established itself in the exploration of soft tissue tumor lesions and aggressive bone lesions that may eventually correspond to a malignant tumor lesion. Although it rarely appears specific, it is very useful for studying the anatomical extension of these lesions and also for orienting the site of the biopsy. We had found a case of benign tumor (a muscular hemangioma) and a case of a tibial lesion of poorly limited contour located at the ankle, of uncertain diagnosis, which could evoke a bone tumor. Adjenou et al. reported only one case of chondroblastoma [10]. The tumoral pathologies are generally rare.

MRI was concordant with the clinic in $97 \%$ of cases with regard to the detection of lesions. MRI is a very sensitive technic for osteoarticular pathology, indeed the MRI-clinical agreement varies in the literature from $86 \%$ to $100 \%$ according to the authors [7] [13] [21].

During this study, some limitations were encountered, including the lack of follow-up of patients, the therapeutic aspects were not considered, so we cannot talk about the future of patients.

\section{Conclusion}

Osteo-articular MRI is the third most performed MRI in our service behind MRI of spine and brain. This study showed that MRI has a significative impact on diagnosis of osteoarticular diseases with a concordance of $97 \%$ with clinic, making it a particularly valuable technique in osteoarticular pathology, allowing a quick start of a suitable therapy. Traumatic and degenerative pathologies were most frequent.

\section{Conflicts of Interest}

The authors declare that they have no conflict of interest with this article.

\section{References}

[1] Carrillon, Y. (2014) Imaging of the Musculoskeletal System. http://www.imosteoarticulaire-carrillon.com

[2] Lépori, L.R. (2004) Mini Atlas Musculoskeletal System. Tome, 2. 
[3] ORS Bourgogne (2013) Disease of the Osteoarticular System. http://www.orsbfc.org/publication/systems-of-articlesystem-chapter-8-from-the-fro nt-table-the-chronic-maladies-in\%20Bourgogne/

[4] Auvray, L., Dumesnil, S. and Le Fur, P. (2001) Health, Care and Social Protection in 2000. http://www.irdes.fr

[5] Dourgnon, P. and Guillaume, R.T. (2012) Health and Social Protection Survey 2010. http://www.irdes.fr

[6] Berenbaum, F. (2010) Diseases of Bones and Joints. Pierre \& Marie Curie University, Paris, 85-86.

[7] Railhac, J.J. and Sans, N. (2003) Osteoarticular and Muscular MRI. 2e éd, MASSON, 82-97.

[8] High Authority of Health (2011) Magnetic Field Power Necessary for the Osteoarticular Exploration of the Limbs by MRI. Saint-Denis la Plaine CEDEX, France. http://www.has-sante.fr

[9] Ould, B.M. (2006) First MRI in West Africa: Problems, Benefits and First Clinical Results. Our Experience in Nouakchott. Radiology Journal, 87, 1426. https://doi.org/10.1016/S0221-0363(06)87468-8

[10] Adjénou, K.V., Amy, A., Adambounou, K., Djagnipko, O., Agoda-Koussema, L.K., Son-Hayel, L., Amadou, L., Tchaou, M., Oniankitan, O., Abalo, A. and N'dakena, K. (2015) Contribution of MRI in the Diagnosis of Knee Pathologies. Rev. CAMES SANTE, 3, 84-88.

[11] World Health Organization (1999) World Health Report. https://www.who.int/whr/1999/en/

[12] Douira, W., Sayed, M., Ammar, C., Jalel, C., Mizouni, H., Louati, H., Aloui, N., Bellagha, I., Ben Ghachem, M. and Mammou, A. (2004) Knee Pathology of the Child: Contribution of the MRI. Children's Hospital, Tunis. https://docplayer.fr/22431049-Pathologie-du-genou-de-l-enfant-apport-de-l-irm.html

[13] Mrabti Fassi, H., Bnouachir, N., Enneddam, H., OualiIdrissi, M., Cherif, E.L., guanouni, N., Adj, S., Essadki, O. and Ousehal, A. (2011) Contribution of MRI in the Diagnosis of Epiphyseal Osteonecrosis in Adults (30 Cases). Electronic Poster. French Radiology Days, Paris-Porte Maillot, France.

[14] Regional Agency of Health (2013) Medical Imaging: Sectional Imaging. 277-293. https://www.paca.ars.sante.fr/contact-3

[15] French Society of Radiology (2005) Guide to the Good Use of Medical Imaging Exams. 102 p. www.irsn.fr/EN/health_professionals/documentation/Documents/guide_bon_usage imagerie.pdf

[16] Bertini, N., Bleichner, G., Cannamela, A., Curvale, G., Faure, C., Jean, P., Kopferschmitt, J., Senez, B. and Verveulen, B. (1995) Sprained Ankle at Reception and Emergencies. Emergency Resuscitation, 4, 491-501. https://doi.org/10.1016/S1164-6756(05)80363-9

[17] Abhishek, A. and Doherty, M. (2013) Diagnosis and Clinical Presentation of Osteoarthritis. Rheumatic Disease Clinics of North America, 39, 45-46.

[18] Mannoni, A., Briganti, M.P., Di Bari, M. and Ferrucci, L. (2003) Epidemiological Profile of Symptomatic Osteoarthritis in Older Adults: A Population Based Study in Dicomano, Italy. Annals of the Rheumatic Diseases, 62, 576-578. https://doi.org/10.1136/ard.62.6.576

[19] Davis, M.A., Ettinger, W.H., Neuhaus, J.M. and Mallon, K.P. (1991) Knee Os- 
teoarthritis and Physical Functioning: Evidence from the NHANES I Epidemiologic Followup Study. The Journal of Rhumathology, 18, 591-598.

[20] Passagia, J.G. (2006) Vascularization of the Upper Limb. http://umvf.omsk-osma.ru/premannee/PASSAGIA_Jean_Guy/PASSAGIA_Jean_G uy_P11/PASSAGIA_Jean_Guy_P11.pdf

[21] Blum, A., Detreille, R., Batch, T., Roch, D., Louis, M., Lecocq, S and Wassel, J. (2010) L'arthro-IMR, Le Gold-Standard Actuel? Journal of Rheumatism Monographs, 77, 222-229. https://doi.org/10.1016/j.monrhu.2010.04.008 